\title{
O CÓDIGO FLORESTAL NA PEQUENA PROPRIEDADE RURAL: UM ESTU- DO DE CASO EM TRÊS PROPRIEDADES NA MICROBACIA DO RIO MIRINGUAVA $^{1}$
}

\author{
The forest code in small rural estates: a case study of three estates in \\ Miringuava's basin
}

\author{
Luiz Anselmo Merlin TOURINHO² \\ Everton PASSOS 3
}

\begin{abstract}
RESUMO
O Brasil é considerado o país com a legislação ambiental mais moderna e abrangente do mundo. Entretanto, o grande número de leis cria dificuldades na compreensão do tema, bem como a sua aplicação e retorno eficientes para a sociedade. Este trabalho visa demonstrar que esse emaranhado de leis dificulta, principalmente a pequena propriedade rural a se adequar às normas impostas, tomando como exemplo o Código Florestal (Lei 4.771, de 15/09/1965), às medidas provisórias que o atualizaram e também às mudanças correlatas constantes da legislação estadual. Ainda discute-se o problema de diversas interpretações dadas a determinados pontos das normas impostas. $\mathrm{O}$ estudo tem como pressuposto a importância de se preservar o meio ambiente, mas considera que essa preservação não pode se sobrepor à sobrevivência do pequeno produtor rural, o qual em suas atividades deve compor o meio ambiente mesmo que transformado, em sua propriedade, em uma unidade territorial sustentável em função do interesse coletivo, adequando-se à legislação ambiental, com incentivos ou alternativas exeqüíveis para que esses produtores rurais possam cumpri-la. Dentre as principais divergências de interpretação estão às relacionadas à Reserva Legal
\end{abstract}

\begin{abstract}
Brazil is considered one of the countries with the most modern and comprehensive environmental legislation. However this large number of Laws creates difficulties for understanding and applying-them with efficiency and environmental return for society. This work is going to show that this confusion of Laws complicates mainly the small rural estate to adapt itself to the imposed norms, examples are the Forest Code (Law 4.771, of 15-09-1965), the emergency measures that brought it up to date and also the recurring changes in the state legislation. It is discussed the problem of diverse interpretations given to same points of imposed norms. The study has assumed the importance of preserving the environment, but considers that this preservation can not overrun the survival of the small rural producer, which in his activities should respect the environment even when transforming his estate in a sustainable territorial unit in function of the collective interest adapting itself to the environmental legislation, with incentives or feasible alternatives to fulfill it. Among the main divergences of interpretation are the Legal Reserve and its forms of compensation. The present work seeks to show in an empirical
\end{abstract}

\footnotetext{
1 Síntese da dissertação defendida no Setor de Ciências da Terra, Departamento de Geografia da UFPR.

${ }^{2}$ Engenheiro Agrônomo - Gestor Ambiental e Auditor Ambiental.

${ }^{3}$ Orientador - Geógrafo, Msc. Agronomia - Ciências do Solo e Dr. Enga Florestal - Manejo Florestal. Prof. Adjunto do Setor de
} Ciências da Terra, Departamento de Geografia. 
e suas formas de compensação. O presente trabalho procura mostrar de forma empírica a aplicabilidade dessa legislação e o quanto ela interfere na propriedade rural. Utilizou-se como modelo três propriedades diferentes, nas quais foram propostos incentivos para a conscientização e adequação à legislação e apresentadas sugestões para adequação das normas.

\section{Palavras-chave:}

Meio ambiente; propriedade rural; legislação ambiental e gestão ambiental.

\section{INTRODUÇÃO}

A sociedade atual preocupa-se cada vez mais com a questão ambiental, sendo a preservação do meio ambiente, sua biodiversidade e o futuro do planeta Terra, sem dúvida alguma, o assunto do momento. Ao pensarmos em mudar os rumos do desenvolvimento em benefício das gerações futuras, devemos considerar a situação atual dos pequenos produtores rurais, que praticam a agricultura de subsistência, nas dificuldades de adaptação à gestão de suas propriedades aos padrões ambientais exigidos por lei.

$\mathrm{Na}$ maioria dos países e também no Brasil os mecanismos de proteção ambiental são compostos por instrumentos de comando e controle, ou seja, por normas e padrões a serem seguidos, atribuindo penalidades aos que não as cumprem.

No meio rural, essa forma de agir na tutela do meio ambiente tem trazido inúmeras dificuldades para que proprietários rurais promovam a gestão ambiental em suas propriedades de modo a garantir o seu sustento. O presente estudo trata de algumas questões decorrentes da aplicação de uma legislação rígida, averiguando suas implicações e ônus na produção agrícola, identificando as barreiras enfrentadas pelos agricultores no cumprimento da referida legislação. O estudo evidenciou, também, aspectos que demonstram que postulados não indicam elementos básicos que permitam ao público envolvido o cumprimento das obrigações impostas.

No estudo de caso da pesquisa destaca-se a análise do papel determinante da burocracia exigida pelos órgãos ambientais, na adequação de uma propriedade rural às normas vigentes.

O estudo decorreu da constatação de que a legislação ambiental no Brasil foi elaborada sem que se tomassem as precauções de socialização do conhecimento e, também, quanto à devida criação de alternativas que permitam planejar as mudanças necessárias. form the applicability of this legislation and how much it interferes with the rural estate. Three different estates were taken as study-object, in which were proposed incentives for the awareness and adaptation to the legislation and also suggestions for adapting to the norms.

\section{Key-words:}

Environment; rural estate; environmental legislation; environmental management.

Com isso, hoje, os conflitos com as práticas agrícolas em áreas ambientalmente sensíveis são inevitáveis, esse é o caso de grande parcela de agricultores no Brasil, a solução é necessária, principalmente, da área onde se propõe esse estudo. É sem dúvida esse o grande desafio. Entendemos que deverão ocorrer mudanças de comportamento impossíveis de serem implementadas a curto prazo, pois envolvem seres humanos que desenvolvem suas práticas agrícolas apegados a fortes laços culturais. Desse modo é natural serem resistentes a inovações que impliquem em mudanças no seu sistema de uso da terra.

A metodologia utilizada para a realização deste trabalho considerou as características da Microbacia do Rio Miringuava, sub-bacia que compõe o alto curso do principal rio do Estado do Paraná, o Rio Iguaçu, localizada próxima (menos de $30 \mathrm{~km}$ ) da capital desse Estado, a cidade de Curitiba, compondo o cinturão verde da Região Metropolitana, suas peculiaridades e também as dificuldades encontradas pelos imigrantes poloneses na ocupação da região.

A pesquisa envolveu estudo de caso em três propriedades rurais: propriedade "A", localizada na comunidade de Antinha com 40,1484 ha; propriedade "B", localizada na comunidade do Avencal com 18,4211 ha; e a propriedade "C" com 19,0801 ha, todas escolhidas aleatoriamente. Não se pode falar em amostragem, pois se assim fosse, maior número de propriedades teriam que ser investigadas para termos uma base científica segura. A metodologia empregada foi com vistas a demonstrar as dificuldades que os proprietários têm em se adequar aos padrões ambientais vigentes. Frisamos por fim, que foi levada em conta a vivência do autor junto às áreas de produção de pequenas propriedades, o que permitiu que os resultados, a seguir apresentados, espelhassem a realidade da atividade rural destas. Realidade essa presente em grande número das microbacias do Estado do Paraná, bem como no território brasileiro. 


\section{HISTÓRICO DA ADOÇÃO DA RESERVA FLORESTAL LEGAL}

LEGISLAÇÃO FEDERAL

No Brasil, a preocupação de se preservar uma parcela das propriedades rurais com florestas nativas já estava presente desde a época do Brasil Colônia, pois mesmo nessa época já havia escassez de madeira apropriada para a construção das embarcações da frota portuguesa. Visando minimizar tal situação, a Coroa expediu cartas régias que declaravam de sua propriedade toda a madeira naval, tais eram denominadas madeira de lei (DEAN, 1996). Nome utilizado ainda nos dias de hoje para se designar as madeiras nobres.

Apenas em 1920, tomou-se a iniciativa de criar uma legislação apropriada, foi quando o então presidente Epitácio Pessoa formou uma subcomissão para elaborar um anteprojeto que daria origem ao Código Florestal.

Foi em 1934 que o projeto transformou-se no Decreto 23.793, que na época ficou conhecido como o Código Florestal de 1934 (AHRENS, 2003).

Esse Código trouxe inúmeras inovações, entre elas a que criou o limite do direito de uso da propriedade, o que foi denominado de quarta parte (DEAN, 1996), a reserva obrigatória de vinte e cinco por cento de vegetação nativa de cada propriedade rural. Mais tarde, em 1965, esse Código foi atualizado e transformado em Lei, a Lei 4.771, vigente até hoje.

Em 1989, a Lei 7.803 alterou alguns artigos do Código Florestal e também acrescentou outros. Um desses acréscimos foi o parágrafo segundo do artigo dezesseis, que instituiu a Reserva Florestal Legal - RL, e também a exigência dela ser averbada à margem da matrícula do imóvel no cartório de registro. Não podendo ser alterada a destinação nos casos de desmembramento e transmissão da propriedade a qualquer título (BRASIL, 1989).

O Código Florestal sofreu outra alteração em 1997 por meio da Medida Provisória 1.551 (28/05/1997), subseqüentemente sofreu novas alterações por meio de medidas provisórias até os dias de hoje. As principais mudanças foram nos artigos primeiro, terceiro, quarto, quatorze, dezesseis e quarenta e quatro da Lei 4.771 (Código Florestal Brasileiro de 15/09/1965). Essas mudanças todas se deram porque as versões de 1934, e também de 1965, do Código, em seu artigo quinze diziam:

Art. 15 - Fica proibida a exploração sob forma empírica das florestas primitivas da bacia amazônica que só poderão ser utilizadas em observância a planos de técnicos de condição e manejo a serem esta- belecidos por ato do Poder Público, a ser baixado dentro do prazo de um ano

Conforme esse artigo, o Poder Público deveria ter regulamentado as formas de manejo da Floresta Amazônica no prazo de um ano, isso desde 1934, mas só o fez em 1994 por meio do Decreto 1.282. Mesmo assim, para conter o desmatamento na Amazônia, o governo federal editou uma Medida Provisória (MP 1.511, de 28/05/1997), em que se determinou a utilização de apenas vinte por cento da área em propriedade localizada na Amazônia, aumentando a porcentagem da Reserva Legal para $80 \%$.

Ocorreram muitas outras alterações sendo que, em 1999, houve uma participação maior da sociedade no debate para uma atualização mais concreta do Código Florestal. Com isso, os setores da sociedade, interessados numa mudança mais radical do Código Florestal, começaram a se articular, sendo que sempre as mudanças se referiram aos artigos dezesseis e quarenta e quatro, que diziam respeito à reserva legal (SOHN, 2004).

Mudança drástica mesmo aconteceu com a Medida Provisória MP 2.166-67, de 24 de agosto de 2001, vigente nos dias de hoje.

Dentre as mudanças introduzidas pelas medidas provisórias, tratando-se de reserva legal, talvez as que tiveram maior impacto foram as que instituíram:

1. As formas de compensação e recomposição da reserva legal (MP 1736-31 de 14/ 12/1998).

2. As que em um primeiro momento admitiram a soma da área de preservação permanente no cômputo do percentual da área de reserva legal (MP 1736-31 de 14/12/1998).

3. As que definiram o aumento da reserva legal na Amazônia Legal e no Cerrado Amazônico para oitenta por cento e cinqüenta por cento, respectivamente (1956-50 de 26/05/2000).

4. A mudança do conceito de reserva legal, em que esta deixou de ter uma conotação econômica para ter um entendimento preserva-cionista (MP 1956-50 de 26/05/2000).

Percebe então que, em menos de uma década, muitas alterações ocorreram na legislação, principalmente no que se refere à reserva legal.

\section{LEGISLAÇÃO ESTADUAL}

No Estado do Paraná não foi diferente. Em três governos a legislação foi alterada várias vezes. Sempre acompanhando o que estava ocorrendo em nível 
federal, o Estado iniciou um trabalho de regulamentação das alterações do Código Florestal, baseando-se nitidamente na lei maior.

Foram convocados os setores interessados para colaborarem na formulação das normas estaduais quanto à reserva legal e áreas de preservação permanente. O debate iniciou-se em 1998, e já em 1999 foi sancionado o Decreto 387, de 03 de março de 1999, que instituiu o Sisleg - Sistema de Recuperação e Manutenção das Áreas de Reserva Florestal Legal (RL) e Áreas de Preservação Permanente (APPs) do Estado do Paraná (SOHN, 2004).

Esse Decreto foi um avanço para se tentar uma reposição florestal no Paraná, por meio da adequação das propriedades quanto à legislação ambiental vigente, sendo bem aceito por todos os setores da sociedade. Alguns dos pontos fortes foram:

1. A área de preservação permanente podia ser utilizada no cômputo do índice da RL, no caso do Estado do Paraná o índice é de vinte por cento do total da área da proprie- dade rural. Com uma nova medida provisória editada pelo governo federal essa utilização mudou a partir de maio de $2000^{4}$;

2. O decreto utilizou os pré-requisitos da Lei Federal para proporcionar ao proprietário rural condições para recompor ou compensar a sua área de $\mathrm{RL}^{5}$;

3. Instituiu um outro parâmetro para compensação da $R L$, que foram os agrupamentos de municípios ${ }^{6}$;

4. Estipulou um prazo para a recomposição das propriedades que não tinham $\mathrm{RL}^{7}$;

5. Instituiu áreas prioritárias para recuperação da RL e das APPs ${ }^{8}$.

A partir do ano de 2002, com a mudança de governo no Estado, a legislação ambiental tomou novo rumo. O governo voltou a discutir mudanças na legislação estadual.

As novas propostas foram pouco discutidas com o público envolvido e interessado, resultando em um novo Sisleg.

TABELA 1 - PERDA DA ÁREA PLANTADA POR CULTURA NO ESTADO DO PARANÁ COM A IMPLANTAÇÃO DA RESERVA LEGAL (20\%) NAS PROPRIEDADES EM ÁREAS PRODUTIVAS

\begin{tabular}{|c|c|c|}
\hline Produto & $\begin{array}{c}\text { Área Plantada } \\
\text { (ha) }\end{array}$ & Perda de $20 \%$ (RL) \\
\hline Aveia preta ............ & 142.031 & 28.406 \\
\hline Café....................... & 130.782 & 26.156 \\
\hline Cana-de-açúcar & 356.891 & 71.378 \\
\hline Cevada... & 51.395 & 10.279 \\
\hline Feijão...... & 388.953 & 77.791 \\
\hline Fumo $\ldots \ldots \ldots \ldots \ldots \ldots$ & 39.095 & 7.819 \\
\hline Mandioca ............... & 157.837 & 31.567 \\
\hline Milho..................... & 1.506 .747 & 301.349 \\
\hline Soja. & 3.278 .394 & 655.679 \\
\hline Trigo ... & 1.076 .363 & 215.273 \\
\hline Subtotal & 6.789 .525 & 1.425 .698 \\
\hline Outras culturas & 1.772 .056 & 354.411 \\
\hline TOTAL & 8.561 .581 & 1.712 .316 \\
\hline
\end{tabular}

\footnotetext{
${ }^{4}$ Pela MP $1956-51$ se o produtor rural utilizar a área de preservação permanente no cômputo da reserva legal deverá ser da seguinte forma: as pequenas propriedades, até $30 \mathrm{ha}$, se utilizada a soma o índice da RL passa de $20 \%$ para $25 \%$; e nas propriedades maiores que 30 ha, o índice passa de $20 \%$ para $50 \%$ do total da área da propriedade.

${ }^{5}$ O proprietário rural que por ventura não tivesse RL, ou apenas parte dela, poderia optar por compensá-la em outra área, desde que dentro da mesma bacia hidrográfica e do mesmo bioma, seguindo parâmetros estabelecidos pelo Decreto 387/99 (Sisleg).

${ }^{6}$ A instituição dos grupamentos foi uma forma de restringir um pouco mais para que não houvesse uma fragmentação muito grande das florestas a serem recompostas, ou uma aglomeração em um único lugar do Estado. Eram dez agrupamentos.

7 A legislação federal estipulou um prazo de trinta anos para a recuperação das RLs nas propriedades, já o Decreto 387/99 adotou o prazo de vinte anos, iniciando em 1999 e terminando em 2018.

${ }^{8}$ As áreas prioritárias foram criadas principalmente para a formação dos corredores ecológicos, formados ao longo dos grandes rios do Estado numa extensão de $5 \mathrm{~km}$ a partir de suas margens, complementando as APPs.
} 
Após as modificações, houve resistência do produtor rural para se adequar às normas, face a problemas ocasionados pelas mudanças freqüentes, que nunca sugeriram alternativas que facilitem a sua adaptação. Com isso, observou-se in loco que a grande maioria das propriedades ficam na clandestinidade.

Estudos feitos pela Faep - Federação da Agricultura do Estado do Paraná, em 2004, com algumas culturas, mostraram que as restrições ao uso da propriedade rural, com a implantação da reserva legal, trouxe para o Estado uma perda de área produtiva em torno de um milhão e setecentos mil hectares, como mostra a Tabela 1, caso cumprissem a legislação ao pé da letra. Já a Tabela 2, mostra que na produção, as perdas po- dem chegar a quinze milhões de toneladas. Quando se fala em Valor Bruto de Produção (VBP) as perdas são ainda maiores podendo chegar a três bilhões de reais, o que indica a Tabela 3.

Na pequena propriedade esse impacto é determinante para a sua sustentabilidade econômica, pois a perda de $20 \%$ do total da área produtiva é muito significante. Dependendo da cultura, a perda pode chegar a quatorze mil reais por ano, sendo que a perda média anual chega a quatro mil reais como mostra a Tabela 4.

Diante de tal quadro, deve-se pensar em alternativas viáveis para a implantação da $R L$ nas pequenas propriedades, medidas que fixem os produtores no campo, diminuindo assim o êxodo rural.

\begin{tabular}{|c|c|c|}
\hline Produto & $\begin{array}{l}\begin{array}{l}\text { Produção } \\
\text { (ton.) }\end{array} \\
\end{array}$ & $\begin{array}{c}\text { Perda de } 20 \% \\
(R L)\end{array}$ \\
\hline Aveia preta & 102.676 & 20.535 \\
\hline Café $\ldots \ldots \ldots \ldots \ldots \ldots$ & 145.260 & 29.052 \\
\hline Cana-de-açúcar & 28.121 .971 & 5.624 .394 \\
\hline Cevada ............... & 73.262 & 14.652 \\
\hline Feijão $\ldots \ldots \ldots \ldots \ldots$ & 452.210 & 90.442 \\
\hline Fumo .... & 77.026 & 15.405 \\
\hline Mandioca .......... & 3.427 .062 & 685.412 \\
\hline Milho...$\ldots \ldots \ldots \ldots$ & 7.563 .628 & 1.512 .726 \\
\hline Soja & 9.381 .663 & 1.876 .333 \\
\hline Trigo & 1.583 .328 & 316.666 \\
\hline Subtotal & 47.321 .322 & 10.185 .617 \\
\hline Outras culturas & 27.337 .602 & 5.467 .520 \\
\hline TOTAL & 74.658 .924 & 14.931 .785 \\
\hline
\end{tabular}

TABELA 3 - PERDA NO VALOR BRUTO DA PRODUÇÃO - VBP POR CULTURA NO ESTADO COM A IMPLANTAÇÃO DA RL (20\%) NAS PROPRIEDADES EM ÁREAS PRODUTIVAS

\begin{tabular}{|c|c|c|}
\hline Produto & VBP (R\$) & Perda de $20 \%$ (RL) \\
\hline Aveia preta & $22.480 .073,00$ & $4.496 .014,60$ \\
\hline Café & 38.4 & ,00 \\
\hline Cana-de & 572.1 & 114. \\
\hline Cevada & 17.1 & 00 \\
\hline eijão. & 309.7 & 0,00 \\
\hline um & 147.7 &, 00 \\
\hline Mar & 198. & 00 \\
\hline Milhc & 5. & $36^{-}$ \\
\hline Soja & 2.741 .000 .0 & $54 \varepsilon$ \\
\hline & 517.200 .00 & 000,00 \\
\hline 4 & 6.001 .300 .00 & 000,00 \\
\hline Dutras culturas & 8.661 .900 .000 & $1.732 .380 .000,00$ \\
\hline VBP Total & $14.663 .200 .000,00$ & $2.932 .640 .000,00$ \\
\hline
\end{tabular}


TOURINHO, L. A. M.; PASSOS, E. O código florestal na pequena...

TABELA 4 - ESTIMATIVA DA PERDA NO VALOR BRUTO DA PRODUÇÃO POR HECTARE EM DIFERENTES CULTURAS EM PEQUENAS PROPRIEDADES (ATÉ 50 HA) COM A IMPLANTAÇÃO DA RL (20\%) EM ÁREA PRODUTIVA

\begin{tabular}{|c|c|}
\hline Produto & $\begin{array}{l}\text { VBP/ha perdido em } \\
\text { Pequenas propriedades }\end{array}$ \\
\hline$\overline{\text { Aveia..... }}$ & 566,63 \\
\hline Café........ & $1.051,15$ \\
\hline Cana-de-açúcar & $5.738,78$ \\
\hline Cevada ......................... & $1.191,13$ \\
\hline Feijão ........................... & $2.850,54$ \\
\hline Fumo.. & $13.525,16$ \\
\hline Mandioca & $4.506,84$ \\
\hline Milho .......................... & $4.290,54$ \\
\hline Soja ............. & $2.993,17$ \\
\hline Trigo .................. & $1.720,22$ \\
\hline Média & $3.843,41$ \\
\hline
\end{tabular}

O IAP tem a informação da porcentagem de RL e de APP que devem ser restauradas, exigível por lei, essas informações estão divididas por bacias hidrográficas como mostram os gráficos 1 e 2 .

Analisando os dois gráficos, observamos que na bacia hidrográfica do Rio Iguaçu, onde se encontra a microbacia do Rio Miringuava, resta muito pouco a restaurar, pois a RL chega a ser negativa, mas o problema é que essa vegetação está distribuída de forma irregular em toda a bacia. Na área do estudo, algumas propriedades não possuem a RL e muitas vezes também a APP.

As limitações ao uso inadequado da propriedade devem existir, entretanto devem ser consideradas as peculiaridades de cada uma, portanto o uso do bom senso para resolver os conflitos é essencial. Não se pode esquecer que o Estado é essencialmente agrícola e foi incentivado por muitos governos para ser um grande produtor de alimentos, como é hoje.

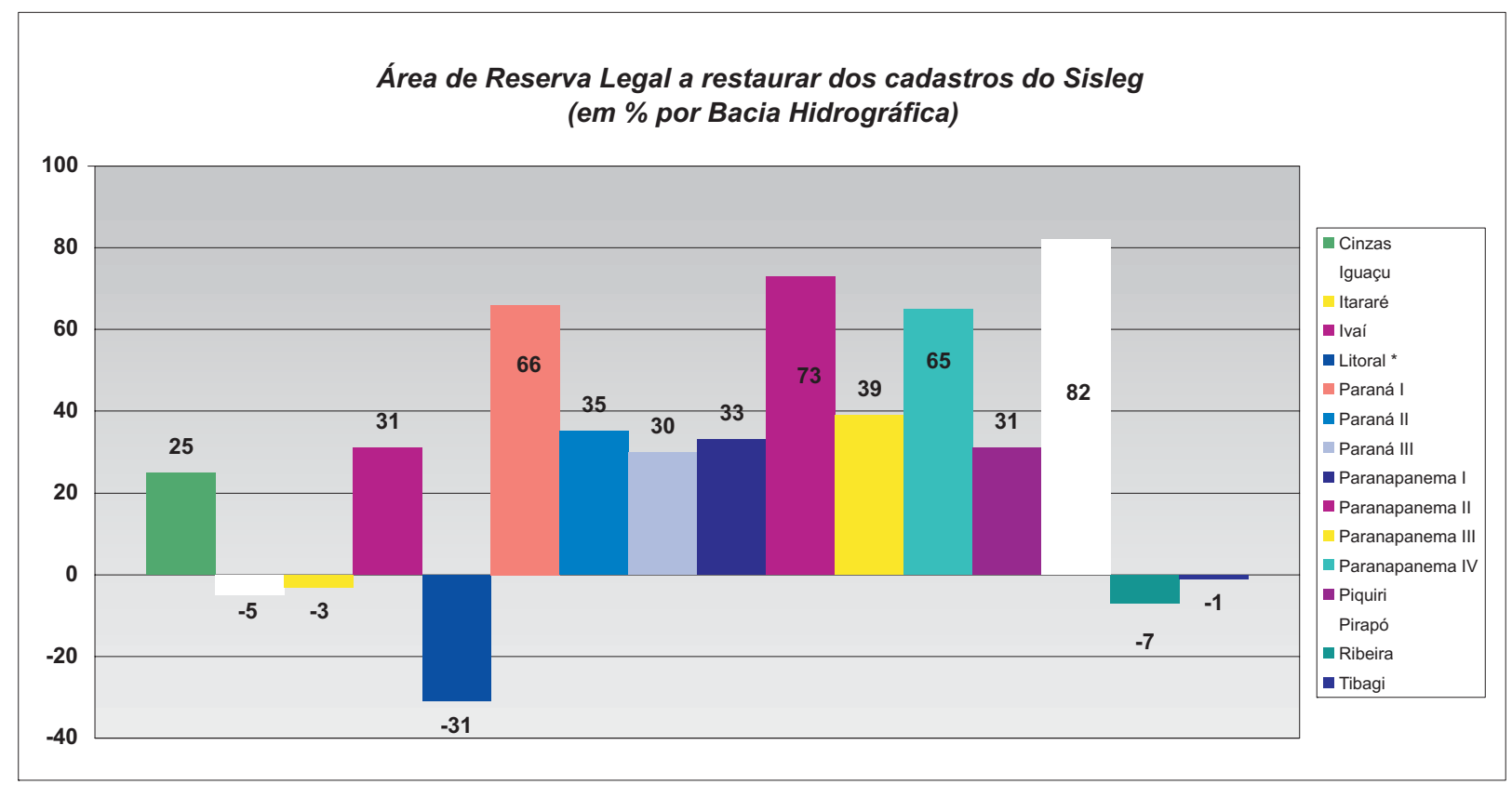

GRÁFICO 1 - MOSTRA A QUANTIDADE DE RL QUE DEVE SER RESTAURADA EM CADA BACIA HIDROGRÁFICA 


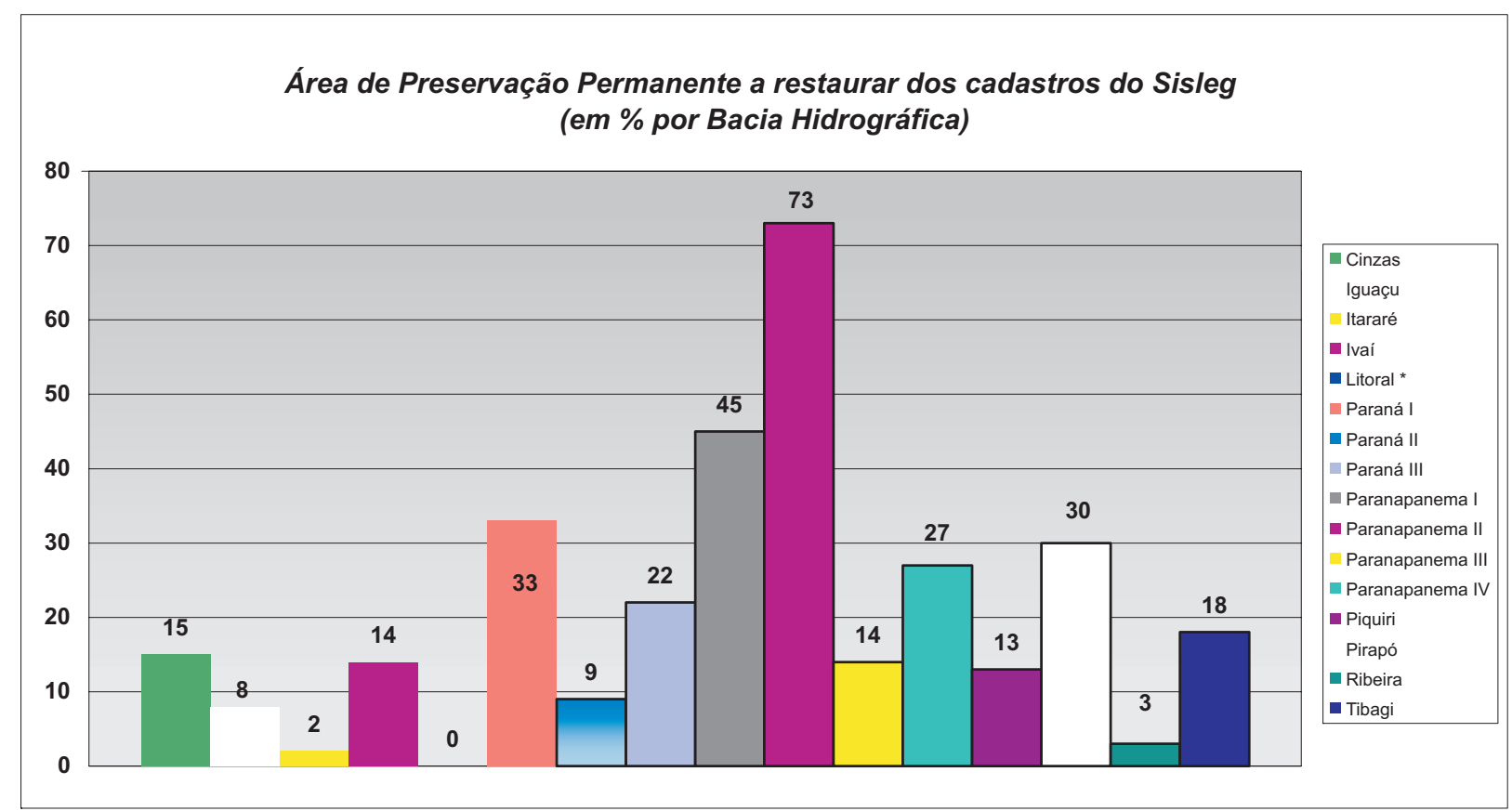

GRÁFICO 2 - MOSTRA A QUANTIDADE DE APP QUE DEVE SER RESTAURADA EM CADA BACIA HIDROGRÁFICA

Fundamentado na legislação federal, o Sisleg vem sendo ajustado às mudanças que foram ocorrendo na esfera federal e estadual.

O principal ponto de discussão, como já foi mencionado, é a implantação da RL e sua averbação. Com o uso das propriedades, muitas vezes incentivados por governos, a legislação se tornou conflitante e nenhum produtor admite perder vinte por cento da propriedade para deixar "crescer mato", expressão utilizada por eles nas entrevistas quando da aplicação do questionário. Devem-se dar alternativas economicamente viáveis para o produtor abandonar a área em questão e se adequar à legislação. Acontece que o governo não tem apresentado tais alternativas.

\section{AS RESTRIÇÕES}

O problema principal dos produtores das três propriedades do estudo é a averbação da RL. Deveria ser simples, mas a burocracia dos órgãos ambientais impede que isso ocorra.

O Estado exige uma série de documentos necessários para ter a anuência do órgão ambiental estadual e assim conseguir averbar a RL.
Com o "novo" Sisleg, as dificuldades aumentaram. O produtor rural deve seguir alguns pré-requisitos se quiser compensar a RL da propriedade em outra área. Esta deve estar:

1. na mesma bacia hidrográfica;

2. dentro do mesmo bioma;

3. dentro do mesmo agrupamento de município; e 4. a área doadora deve estar com o percentual de floresta acima do exigido legalmente.

Encontrando uma outra propriedade que cumpra esses quatro pré-requisitos, o agricultor poderá fazer a compensação da RL da sua propriedade, nesta outra.

A compensação em outra propriedade é permitida desde que a original não esteja localizada dentro dos Corredores de Biodiversidade ${ }^{9}$ ou no entorno de UCs que seriam áreas prioritárias para manutenção da RL.

Entretanto essa restrição dos Corredores fere o princípio de isonomia da Constituição, embora alguns estudiosos pensem diferente, ela cria um tratamento diferenciado perante a Lei.

${ }^{9}$ São áreas estipuladas pelo governo, que se situam ao longo dos grandes rios do Estado como se fossem Mata Ciliar numa faixa de cinco quilômetros de cada lado. 


\section{PROPOSTAS E ALTERNATIVAS}

Durante o trabalho, constataram-se as dificuldades na adequação do produtor rural à legislação, ao mesmo tempo em que se identificou algumas alternativas, que podem ser viáveis para alguns e para outros não, dependendo da atividade e das condições financeiras de cada proprietário, caberá a este optar pela melhor alternativa.

\section{COMPENSAÇÃO DA RL}

A primeira alternativa permite a compensação da $\mathrm{RL}$ em outra área, desde que se cumpra com os prérequisitos, nesse ponto acha-se que os pré-requisitos deveriam ser apenas os ditados pela Lei Federal (MP 2.166-67, 24/08/2001), acrescentando alguns agrupamentos de municípios que poderiam ser em número de dez, como anteriormente era estabelecido no Sisleg, excluindo o pré-requisito dos corredores de biodiversidade e substituindo pelo incentivo à recuperação das APPs.

Essa alternativa poderia ser aproveitada pelos proprietários das áreas " $A$ " e "B", que não possuem RL e poderiam compensar na " $C$ ", que tem excesso de floresta.

O grande desafio é encontrar soluções a curto prazo que possam trazer algum benefício econômico ao produtor.

\section{CRÉDITOS DE CARBONO PARA RECUPERAÇÃO DE RLS E APPS}

A ratificação do Protocolo de Kyoto pela Rússia abriu um grande mercado de créditos de carbono no Brasil, que poderia ser uma alternativa para o pequeno produtor rural. Ele teria uma renda anual, quantificada pela quantidade de carbono que sua floresta é capaz de "seqüestrar" durante um período aproximado de trinta anos. Essa alternativa serviria, por exemplo, para os proprietários das áreas " $A$ " e "C", principalmente para o proprietário " $C$ ", que tem a sua área coberta com florestas e não pode desflorestar. Poderia ter uma fonte de renda sem precisar usar a terra, mas o Protocolo de Kyoto não permite a comercialização de créditos em áreas com o dever legal de serem recompostas. Portanto, ainda está em discussão a inclusão dessas áreas, quando isso ocorrer será um ganho para o meio ambiente e também para o produtor rural.

\section{SISTEMAS AGROFLORESTAIS - SAF}

Uma outra alternativa seria a utilização da RL com Sistemas Agroflorestais (SAF). Das três propriedades que estudamos, apenas a propriedade "C" não estava utilizando o SAF, as outras duas já o utilizavam.

Existem oportunidades na legislação vigente que viabilizam o uso da SAFs por parte dos pequenos agricultores, visando à recuperação de RL e APPs. O aproveitamento dessas oportunidades por parte dos agricultores depende em grande parte da realização de estudos mais aprofundados que visam à adoção dessa tecnologia, bem como a avaliação sobre a viabilidade econômica do uso destas pelo pequeno produtor.

Portanto, para cumprir as restrições impostas pela legislação, deve-se buscar sistemas de uso múltiplo da floresta, para que, assim, o produtor rural tenha o retorno econômico necessário.

\section{CÔMPUTO DA APP PARA O ÍNDICE DA RL}

Uma alternativa a curto prazo para resolver o problema no campo, como as autuações dos órgãos ambientais, da promotoria, de ONGs e outros, seja uma discussão sobre o Código Florestal e sua implementação, modificando-o nos pontos necessários. Notamos que na aplicação da legislação ainda existem muitas dúvidas, sejam no aspecto prático sejam na efetividade de preservação ambiental.

A proposta de se poder computar a APP no índice de RL (seria da RL na APP) parece ser a melhor alternativa desde que se iniciou as discussões sobre a atualização do Código Florestal. Além de incentivar a recuperação das APPs, que já seria um grande feito para o meio ambiente, regularizaria a situação das propriedades rurais quanto à legislação. Tal proposta, se implementada, beneficiaria os dois lados, o ambiental e o produtor rural.

A situação atual de uso da maioria das propriedades rurais está representada na Figura 1.

Nessa forma de uso não está sendo cumprida a legislação ambiental.

O ganho ambiental seria extraordinário com a conscientização dos agricultores na aceitação de que se acrescidas as APPs no cômputo da RL, principalmente no caso das matas ciliares ao longo da rede de drenagem ${ }^{10} \mathrm{e}$ outras áreas de preservação de uma bacia hidrográfica. Pois, segundo BIGARELLA; PASSOS

\footnotetext{
${ }^{10} \mathrm{~A}$ drenagem de uma região depende não só da pluviosidade e da topografia, como também da cobertura vegetal, do tipo de solo, da litologia e da estrutura geológica. Terrenos relativamente impermeáveis apresentam densa rede de drenagem, enquanto os mais permeáveis possuem densidade menor (BIGARELLA; PASSOS et al. 2003).
} 


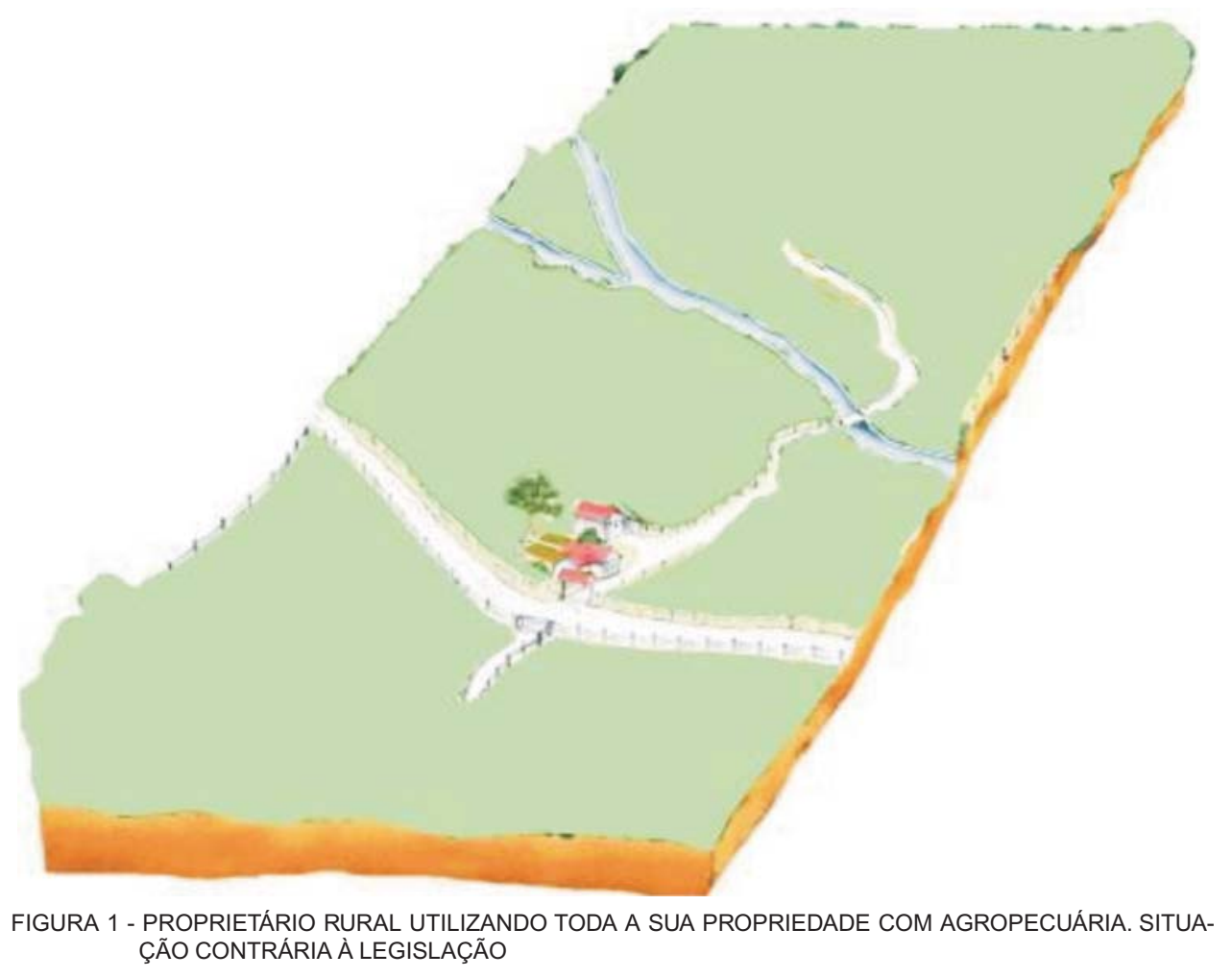

et al. (2003), os rios apresentam-se como um dos mais notáveis agentes erosivos geológicos. Estes são responsáveis pela escultura do modelado do relevo, como também ao longo da história tem demonstrado ter um papel importante no condicionamento ambiental da vida do homem.

A Figura 2 mostra uma propriedade com todas as suas atividades econômicas e a mata ciliar (APP), esta tendo também a função de RL. Existindo um conjunto de propriedades ao longo dos rios com essa configuração não seria bom para o meio ambiente?

Com a legislação atual, o produtor deveria deixar a sua propriedade como mostra a Figura 3, uma propriedade com RL, APP e todas as outras exigências da legislação. Entretanto, essa forma ideal de uso da terra limita economicamente algumas propriedades, como exemplo podemos citar as analisadas neste trabalho.

Observa-se que da legislação vigente surgem outras alternativas, que talvez em um primeiro momento não sejam viáveis, mas com um planejamento podem ser utilizadas para viabilizar a sustentabilidade ambiental de pequenas propriedades. Como exemplo disso temos: o imposto ambiental; o arrendamento de florestas ou ainda os condomínios, essas outras alternativas serão descritas a seguir. 


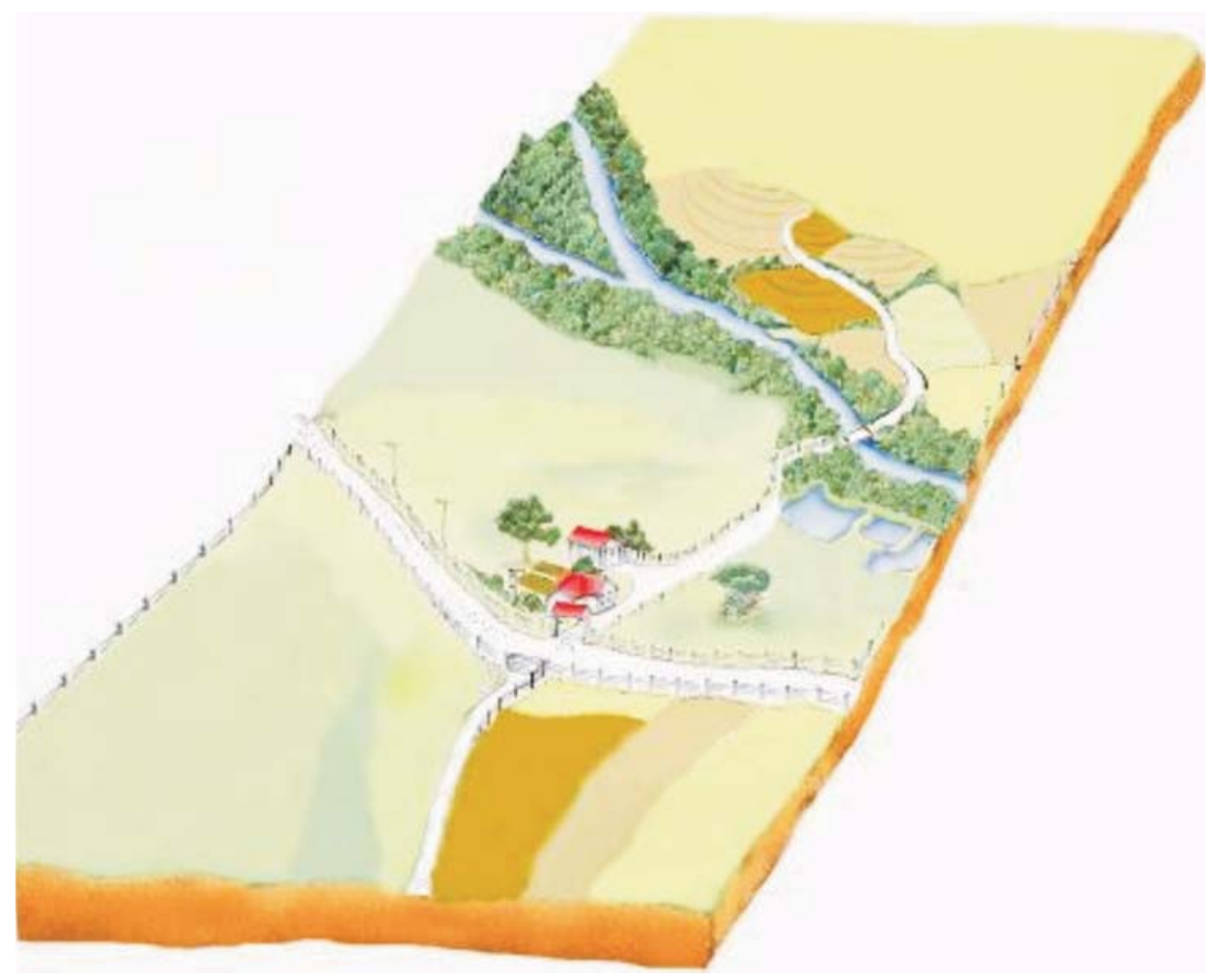

FIGURA 2 - PROPRIEDADE RURAL USANDO A APP PARA COMPOR OS 20\% DA RL

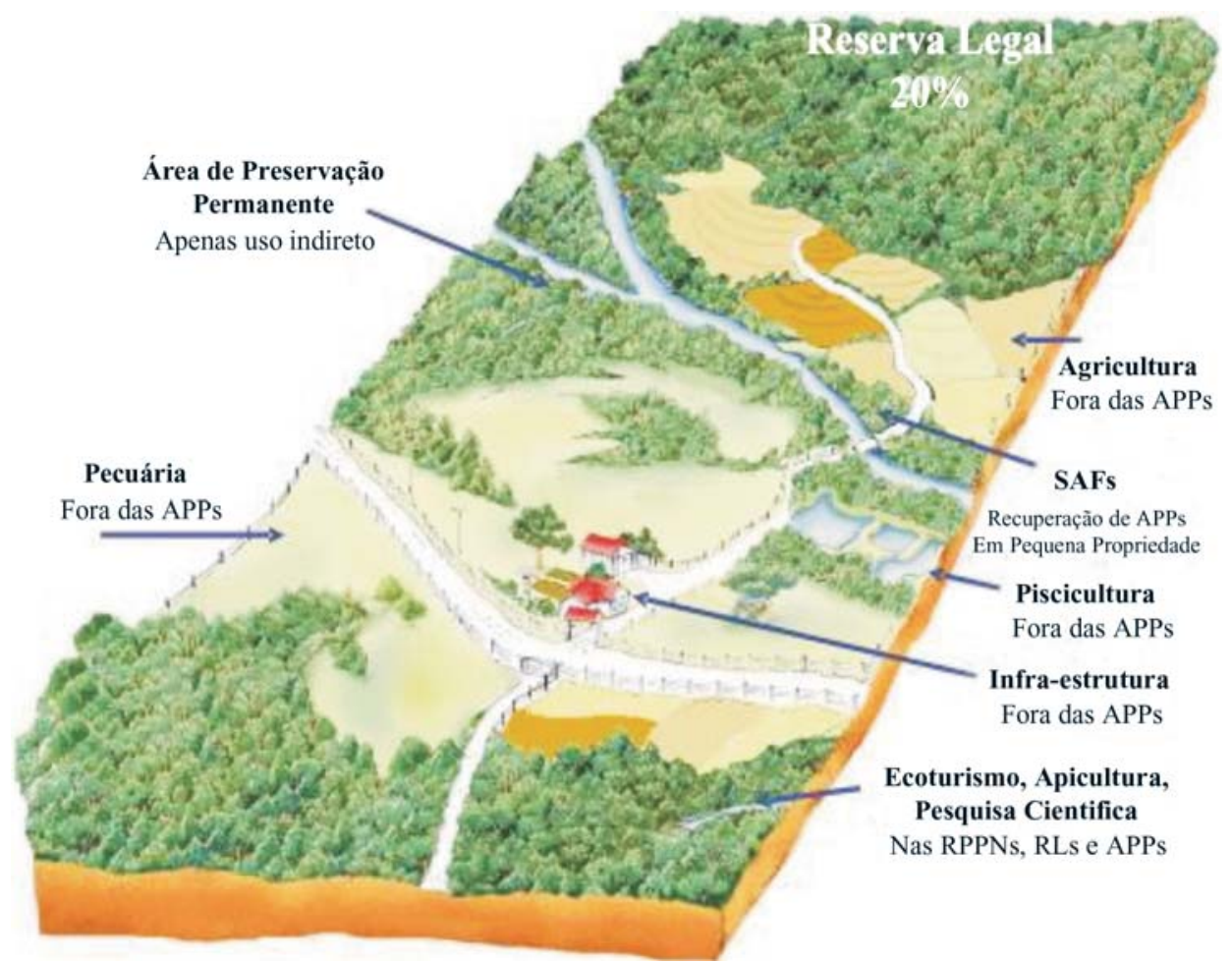

FIGURA 3 - PROPRIEDADE CUMPRINDO A LEGISLAÇÃO AMBIENTAL VIGENTE 


\section{IMPOSTO AMBIENTAL}

Uma outra alternativa, que também poderia ser favorável ao produtor rural, é a implementação de um imposto ambiental, que toda a sociedade urbana pagaria para a manutenção do meio ambiente equilibrado. Ou seja, o produtor rural não pode arcar com os problemas ambientais sozinho, sendo que o poluidor de fato é o meio urbano.

Os rios que abastecem as cidades geralmente nascem nas propriedades rurais, quando este atravessa a cidade é que recebe a maior carga de poluição. Conforme a idéia lançada pela Constituição que "é dever de toda a coletividade manter e proteger o meio ambiente", o meio urbano deveria contribuir para a preservação do meio rural, pois dessa forma a preservação de florestas e nascentes é dever de todos. Como também, o meio urbano deveria manter as áreas de risco desabitadas, assim como as margens dos rios que cortam as cidades deveriam ter as APPs recompostas, mas em geral isso não acontece.

Em virtude disso, um imposto ambiental serviria para ajudar o agricultor a recompor o meio ambiente para a coletividade. Esse imposto poderia ser um tributo municipal, distribuído num fundo gerenciado por integrantes de toda a sociedade, em que mediante projetos de melhoria ao meio ambiente poderiam ser aplicados, como na recuperação de APPs e RLs.

\section{ARRENDAMENTO DE FLORESTAS PARA COMPEN- SAÇÃO DA RL}

Outra opção, o sistema de arrendamento, principalmente para aqueles que cumprem o Código Florestal (Lei 4.771/65), mantendo suas florestas intactas e às vezes deixando até mais do que a Lei exige, tais produtores se sentem injustiçados porque não podem utilizar essas áreas - como o proprietário da área "C", por exemplo -, esse sistema (de arrendamento) da floresta excedente está contido na MP 2.166-67 (art. 44, § 5), falta apenas a regulamentação para a implementação.

Nesse caso, o excedente de floresta, na propriedade, que está por lei impedido de ser convertido em área para produção agropecuária poderá, por meio de um contrato de arrendamento, ser cedido para outro proprietário que esteja sem a $\mathrm{RL}$ e queira regularizar a situação. $\mathrm{O}$ aluguel desse excedente de floresta resolveria o problema de ambos. No caso do produtor que possui a área preservada, este teria um ganho econômico que anteriormente não the era proporcionado, e o que não possui a Reserva Legal, poderia regularizar a sua situação perante a legislação vigente.

\section{CONDOMÍNIOS FLORESTAIS PARA COMPENSAÇÃO DARL}

Outra forma de adequação são os Condomínios Florestais, que a legislação também permite (MP 2.16667 , art. $44, \S 11^{\circ}$ ), desde que seja respeitado o percentual legal de cada imóvel e haja aprovação pelo órgão ambiental.

Vários produtores poderiam se unir, comprar uma área de floresta, quotizar-se proporcionalmente ao tamanho da área de cada propriedade, e transferir para essa quota a sua RL, chamado pela Lei de condomínio privado, que pode ser doado ao Estado em forma de parque, ou então, formar uma Reserva Particular do Patrimônio Natural (RPPN), com a responsabilidade dos proprietários rurais, e com a devida isenção de impostos.

Apesar de listadas aqui algumas alternativas visando ao cumprimento da legislação, deve-se ainda considerar as peculiaridades de cada caso para que não ocorram injustiças.

\section{CONCLUSÃO}

Para que se crie um ambiente favorável à sustentabilidade, é necessário que sejam revistos uma série de pressupostos que dão suporte aos instrumentos e mecanismos da gestão ambiental. Há que ser salientada a predominância dos instrumentos regulatórios, do tipo comando e controle.

Esses são instrumentos muito rígidos que atingem de modo linear todas as unidades de produção. De modo mais contundente a pequena propriedade rural. Esses instrumentos só serão eficazes se, além da capacidade de estabelecer regras, haja também uma boa estrutura dos órgãos fiscalizadores. O que infelizmente hoje não acontece.

O fator fundamental para que a produção agrícola continue crescendo, sem que se tenha que sacrificar o meio ambiente, é a possibilidade de se reduzir o impacto ambiental por unidade de atividade produtiva. Somente políticas que introduzam maior eficiência ambiental nas atividades econômicas podem assegurar a compatibilidade entre o crescimento econômico e a sustentabilidade ambiental.

A questão ambiental não pode se resumir a expressões como é proibido, é vedado, não é permitido, ou então a autuações, embargos, interdições, sanções penais. Deve haver a proposta da construção de conhecimentos por meio da análise das situações reais. Essa forma de agir produziria intervenções humanas adequadas às situações singulares.

Assim, no decorrer deste trabalho, explorou-se a questão da atualização dos dispositivos legais e ade- 
quação dos mesmos para uma realidade de campo bastante distinta. Procurou-se mostrar que, na prática, a implementação da legislação não é tão simples e que existem fatores que fogem do alcance da lei.

Finalmente, desta pesquisa com intuito informativo e educacional editou-se também uma cartilha
(TOURINHO, 2005) com instruções básicas para o produtor rural se adequar quanto a RL e sua APPs, intitulada Propriedade Rural Legal, onde se procurou mostrar ao produtor rural que ele não pode ficar alheio à legislação, deve conhecer e se preocupar com seus direitos e deveres de cidadão.

\section{REFERÊNCIAS}

AHRENS, S. O "novo" código florestal brasileiro: conceitos jurídicos fundamentais. In: CONGRESSO FLORESTAL BRASILEIRO, 8. São Paulo: Sociedade Brasileira de Silvicultura, 2003. p. 15.

BENJAMIN, A. H. V. Direito ambiental das áreas protegidas: o regime jurídico das unidades de conservação. Rio de Janeiro: Forense Universitária, 2001. p. 5547.

BIGARELLA, J. J.; BECKER, R. D.; PASSOS, E. Estrutura e origem das paisagens tropicais e subtropicais - intemperismo biológico, pedogênese, laterização, bauxitização e concentração de bens minerais. v. 2. Florianópolis: UFSC, 1996. p. 432-876.

BIGARELLA, J. J. Estrutura e origem das paisagens tropicais e subtropicais - processos erosivos, vertentes, movimentos de massa, atividade endógena, superfície de erosão, compartimentação do relevo, depósitos correlativos e ambiente fluviais. v. 3. Florianópolis: UFSC, 2003. p. 877-1436.

BRASIL. Decreto-lei n. 23.793, de 23 de janeiro de 1934. Aprova o Código Florestal Brasileiro. Diário Oficial da República Federativa do Brasil. Rio de Janeiro, 1934.

BRASIL. Lei n. 4.771, de 15 de setembro de 1965. Institui o novo Código Florestal Brasileiro. Diário Oficial da República Federativa do Brasil. Brasília, 1965.

BRASIL. Lei n. 6.938, de 31 de agosto de 1981. Institui a Política Nacional do Meio Ambiente. Diário Oficial da República Federativa do Brasil. Brasília, 1981.

BRASIL. Lei n. 7.803, de 18 de julho de 1989. Altera a redação da Lei 4.771, de 15 de setembro de 1965. Diário Oficial da República Federativa do Brasil. Brasília, 1989.

BRASIL. Medida Provisória n. 2.166-67, de 23 de agosto de 2001. Altera os parágrafos $1^{\circ}, 4^{\circ}, 14^{\circ}, 16$ e 44 , e acresce dispositivos à Lei n. 4.771, que institui o novo Código Florestal Brasileiro. Diário Oficial da República Federativa do Brasil. Brasília, 2001.

BRASIL. Resolução Conama 20/86. Resolução do ConseIho Nacional de Meio Ambiente - Conama, de 18 de junho de 1986. Diário Oficial da República Federativa do Brasil. Brasília, 1986.
CARVALHO, C. G. de. Introdução ao Direito Ambiental. 2. ed. São Paulo: Letras e Letras. p. 330.

DEAN, W. A ferro e fogo: a história e a devastação da Mata Atlântica brasileira. São Paulo: Companhia das Letras, 1996.

EHLERS. E. Agricultura sustentável: origens e perspectivas de um novo paradigma. 2. ed. Guaíba: Agropecuária, 1999.

FERREIRA, I. S. Tutela penal do patrimônio cultura. São Paulo: RT, 1995. p. 126.

IAROCHINSKI, U. Saga dos polacos. Curitiba, 2000.

IBGE. Posição geográfica do município de São José dos Pinhais. Curitiba, 1994.

LINHARES, M. Y.; SILVA, F. C. T. da. História da agricultura brasileira: combates e controvérsias. Rio de Janeiro: Campus, 1999.

LOPES, M. A. R. Ética e administração pública. São Paulo: RT, 1993. p. 88.

MAACK, R. Geografia física do estado do Paraná. 2. ed. Rio de Janeiro: José Olympio, 1981.

MACHADO, P. A. L. Direito ambiental brasileiro. 4. ed. São Paulo: Malheiros, 1992. p. 606.

PARANÁ. COMEC; DEE. Dados básicos da Região Metropolitana de Curitiba. Curitiba, 1985.

PARANÁ. et al. Diretrizes ambientais para o desenvolvimento integrado da Região Metropolitana de Curitiba: plano diretor de manejo florestal. Curitiba, 1988.

PASSOS, E. Mapeamento geomorfológico de bacias de mananciais na Região Metropolitana de Curitiba (inédito).

PIERANGELLI, J. H. (Comp.). Códigos Penais do Brasil. Evolução Histórica. Bauru: Jalovi, 1980.

PRADO, L. R. Direito penal ambiental: problemas fundamentais. São Paulo: RT, 1992. p. 110.

RODERJAN, R. V. Os curitibanos e a formação de comunidades campeiras no Brasil meridional. Curitiba, 1992.

SÁ, E.; CARRERA, F. Planeta Terra: uma abordagem de direito ambiental. Rio de Janeiro: Lúmen Júris, 1999. p. 185. 
SANQUETTA, C. R. Os números atuais da cobertura florestal do Paraná. Curitiba, 2003.

SARACENO, E. Conceito de ruralidade: problema de definição em escala européia. Disponível em: <http:// www.eco.unicamp.br/indexie.html> Acesso em: 22/10/2003.

SHON, S. Gestão descentralizada de um sistema de manutenção, recuperação e proteção da reserva florestal legal e áreas de preservação permanente - SISLEG. Disponível em: <http://ambicenter.com.br/an01020801.htm> Acesso em: 26/ 12/2004.

SZMRECSÁNYI, T. Pequena história da agricultura no Brasil. São Paulo: Contexto, 1997.
TOURINHO NETO, F. da C. Crime ambiental. Correio Brasiliense - Caderno Direito e Justiça, Brasília, p. 5, 1997.

VEIGA, J. E. da. O desenvolvimento agrícola: uma visão histórica. São Paulo: Edusp/Hucitec, 1991.

WACHOWICZ, R. C. Aspectos da imigração polonesa no Brasil. Curitiba: UFPR, 1970.

WAINER, A. H. Legislação ambiental brasileira: subsídios para a história do direito ambiental. Rio de Janeiro: Forense, 1991. p. 138. 